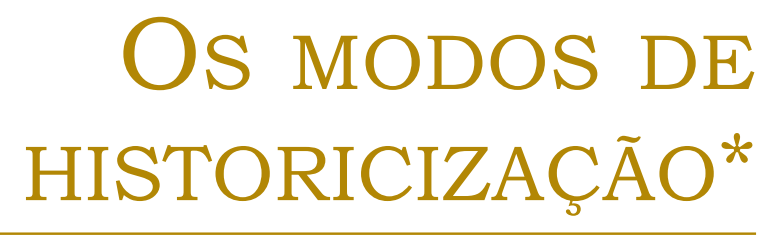

Sylvain Auroux ${ }^{* *}$

(CNRS Université de Paris | França)

Tradução do francês por:

Jacqueline Léon ${ }^{* * *}$

(CNRS Université de Paris | França) http://orcid.org/0000-0002-6506-166X

Marli Quadros Leite ${ }^{* * *}$

(USP | São Paulo | Brasil)

(iD) http://orcid.org/0000-0002-8417-0140

Como citar este artigo: AUROUX, S. Os modos de historicização. Tradução Jacqueline Léon e Marli Quadros Leite. Todas as Letras - Revista de Lingua e Literatura, São Paulo, v. 23, n. 1, p. 1-12, jan./abr. 2021. DOI 10.5935/1980-6914/eLETLL216745

Submissão: março de 2021. Aceite: março de 2021.

Resumo: Ser historiador das ciências é ser capaz de estabelecer cronologias e linhas causais (este último ponto é o que distingue o historiador do historiógrafo, que apenas relata a história, ainda que a narrativa seja em si uma trama explicativa); ainda mais, é ser capaz de construir representações e explicações.

Palavras-chave: História das ciências. História da linguística. Meta-história e cronologia. Linha causal. Horizonte de retrospecção.

\footnotetext{
* A ideia inicial deste artigo veio-me quando eu me propus a escrever uma contribuição para a Festschrift d'Anders Ahlqvist [Festividades de Anders Ahlqvist]; infelizmente não pude terminá-la a tempo. É então a esse impecável amigo que eu o dedico.

** UMR7597 Laboratoire d'Histoire des Théories Linguistiques (HTL), França. E-mail: auroux.sylvain@wanadoo.fr

*** UMR7597 Laboratoire d'Histoire des Théories Linguistiques (HTL), França. E-mail: jleon@linguist.univ-paris-diderot.fr

**** Universidade de São Paulo (USP), UMR7597 Laboratoire d'Histoire des Théories Linguistiques (HTL), São Paulo, SP, Brasil. E-mail: mqleite@usp.br
} 


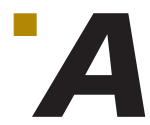

s representações supõem objetos. Chamamos dominio de objetos históricos um conjunto qualquer de entidades susceptíveis de ser o apoio empírico do trabalho do historiador. É certo que esse domínio deve possuir algumas propriedades particulares, senão todo domínio do objeto se tornaria histórico. Não é nosso projeto abordar essa questão neste breve artigo ${ }^{1}$. Dizemos simplesmente que as características principais do domínio do objeto histórico são a emergência de novas entidades e a irreversibilidade das sequências emergentes, o que significa que esses objetos devem ter uma relação intrínseca com o tempo.

O historiador das ciências não pode se contentar em utilizar uma temporalidade extrínseca, o que valeria dizer que as representações que ele constrói situam simplesmente os seus objetos (que são eles mesmos representações) em um quadro temporal, uma cronologia, ainda que essa cronologia seja a condição mínima da história. Os conhecimentos não são acontecimentos e, então, não têm data; são suas eventuais aparições que têm data e que nós as datamos. Além do mais, isso não é tão fácil, pois, para isso, é preciso construir uma permanência ou uma identidade para os conhecimentos (o teorema de Pitágoras, a teoria do imperfeito ${ }^{2}$ ). Não haveria simplesmente história se essa identidade fosse dada ou então nós não nos contentaríamos em fazer uma história ao inverso: eu tomo um conhecimento X, que eu sei identificar no meu horizonte profissional (sou capaz de dar um curso sobre isso diante dos estudantes) e tento descrever o que havia antes da aparição de $\mathrm{X}$ (aproximações de $\mathrm{X}$, trechos de $\mathrm{X}$, nada de X, talvez mesmo "verdadeiros erros"). Naturalmente, é o que se faz muito frequentemente: nos anos 1960, um manual da história da linguística se esforçava para fazer a história da dupla articulação de Martinet desde os gregos; hoje, o mesmo tipo de historiador, também pouco profissional, poderia considerar fazer a "história" da linguística a partir da gramática gerativa. Isso conduz inevitavelmente a utilizar a noção teleológica ${ }^{3}$ de "precursor". Se descubro (isto é, se construo uma representação ad hoc) que o conhecimento X de Y, produzido em t, possui uma "semelhança notável" com o conhecimento A de B, produzido em $\mathrm{t}+\mathrm{n}$, eu nada explico se digo que $\mathrm{X}$ é o "precursor" de B: não faço somente repetir de um outro modo que há uma "semelhança notável" entre X e A. O trabalho do historiador é explicar por que X é construído como ele é e ver se há (ou não) uma linha causal entre Y e B. Assim, eu não ganho nada, do ponto de vista da explicação, se, observando que os primeiros gramáticos do islandês apresentam as "letras" dessa língua a partir de diferenças fonéticas mínimas explicando-as sobre pares de palavras em oposição, eu afirmo simplesmente que esses gramáticos foram os "precursores" da fonologia. Irei, assim, mais longe se notar que o problema é apresentar quadros segundo a classificação aristotélica de encaixe de categorias separadas por diferenças específicas. Será preciso, além disso, seguir essa representação, testar eventualmente sua estabilidade no curso do tempo e, finalmente, ver se ela tem uma relação causal com a fonologia.

\footnotetext{
Nós o abordamos em Auroux (1998) com base no conceito de "ciências onto-históricas".

2 A questão da identidade dos conhecimentos é um problema delicado que não podemos abordar aqui (ele concerne à noção mesma de verdade). Nós nos contentaremos simplesmente em postular que ele é solucionável e que há um sentido para considerar essa identidade como um fato. Em outras palavras, nós não adotamos o relativismo.

3 De maneira geral, o historiador deve se esforçar para não recorrer à teleologia, ou seja, explicar o passado pelo futuro. Ele deve utilizar a explicação causal que vai do passado ao futuro; ele pode evidentemente utilizar o futuro virtual do "programa de pesquisa", nos limites, na medida em que esse é uma causa da produção dos conhecimentos.
} 
Na prática do historiador, a questão da história pode se resumir em uma questão de dimensões e de relações entre essas dimensões quando se constrói a representação histórica. Pode-se considerar que essas dimensões são em número de cinco:

1. um sistema de objetos (isto é, uma representação construída a partir do dominio de objetos);

2. um parâmetro temporal;

3. um parâmetro espacial;

4. um sistema de parametrização externa ligando o sistema de objetos ao seu contexto;

5. um sistema de interpretantes.

As dimensões constituídas pelo sistema de parametrização ligado ao contexto, e este ligado ao espaço, podem ser nulas ou muito fracas (estamos então em uma concepção extremamente idealista da história); mas pode-se também hipertrofiar o sistema de parametrização externa (abordagem puramente sociológica, por exemplo). A existência de um parâmetro espacial pode surpreender; ele corresponde evidentemente ao fato de que os acontecimentos são situados num aqui-agora. Contudo, podem-se escolher diferentes pesos para cada um desses parâmetros, um em relação ao outro, como diferentes relações de ordem entre eles. A história das línguas, como foi desenvolvida no mundo germânico no século XIX, faz quase abstração da dimensão espacial e somente utiliza a dimensão da temporalidade (a árvore das línguas), que é primeira e quase autônoma. Pode-se descrever também o que se passa em um espaço dado. Para fazer compreender o que se entende por isso, imaginemos um mar de lama sobre uma superficie dada; bolhas explodem na superfície, montículos aparecem ou desaparecem; as ligações causais que é preciso descrever não são somente relações de sucessão, mas também relações de contiguidade. Não é totalmente inexato sustentar que o modelo Heródoto de aproximar a história política é mais espacial (e, portanto, antropológico, tanto quanto geográfico), enquanto o modelo Tucídides é mais temporal (encadeamento de res gestae [coisas dadas/acontecidas]). No século XVI, os autores da História natural e moral, como José de Acosta (1589, História natural e moral das Índias ocidentais), seguiram o modelo Heródoto. É claro, contudo, que, para que haja história, a temporalidade não deve ser representada como indiferente no domínio dos objetos, simples dimensão na qual chegam e/ ou na qual nós os representamos ${ }^{4}$, ela deve corresponder a uma característica interna e essencial ${ }^{5}$. Pode-se definir essa característica dizendo que B é "histórico", se não há existência sem um B que o precede. O sistema de interpretantes contém notadamente as pré-concepções da forma dos objetos, de sua relação com a temporalidade e de seu estatuto ontológico.

$\mathrm{O}$ ato de saber (a produção do conhecimento) não é em si sem relação com a temporalidade. Para simplificar, imaginemos um sujeito $\mathrm{S}$ na sua atividade

\footnotetext{
4 Isso implica que a concepção kantiana da temporalidade (a dimensão subjetiva na qual vemos as coisas) é insuficiente.

5 Isso implica que o modelo platônico de temporalidade (o tempo é a imagem móvel da eternidade) é inadequado: imaginemos as luzes de uma vila se refletindo nas águas do porto; o tempo é como essas pequenas ondas que deformam a imagem das luzes ao desejo do vento, ele é inessencial à realidade por trás da imagem. Se as ciências têm uma história no sentido em que entendemos aqui, é preciso recusar aos conhecimentos o estatuto das ideias - modelos platônicos.
} 
cognitiva. Ele dispõe de competências adquiridas e desenvolvidas no decorrer de sua formação. Quando ele decide resolver um problema, dispõe igualmente de conhecimentos; ora, esses conhecimentos foram necessariamente produzidos antes da atividade cognitiva em questão. Nós nomeamos horizonte de retrospecção o conjunto desses conhecimentos antecedentes (AUROUX, 1987). Um horizonte de retrospecção pode ser estruturado de múltiplas maneiras. Os conhecimentos podem figurar de maneira indistinta como conhecimentos comuns. Mas eles podem também ser indexados, com autores, e também datas. A existência de horizontes de retrospecção testemunha que o conhecimento tem necessariamente relação com o tempo: não há conhecimento instantâneo, o que não significa que o objeto do conhecimento ou seu valor sejam temporais, como sustenta o relativismo.

Qualquer que seja S (quero dizer um grego, um indiano, sábio da Renascença ou nosso contemporâneo), ele sabe bem que há outros autores além dele, ou seja, ele tem consciência de entrar em um conjunto, e de lhe pertencer; ele sabe também que alguns desses autores estão mortos e, às vezes, que vários séculos os separam. Isso não implica que ele apreenda o conhecimento como uma entidade histórica. A Física de Aristóteles se dá conta continuamente das teorias de Platão, de Demócrito, de Parmênides e de outros ainda. Aristóteles sabe incontestavelmente que ele vem depois; ele foi aluno de Platão. Não é por isso que as teorias desses autores sejam, para ele, marcadas de historicidade. Seu horizonte de retrospecção é estruturado sem que a temporalidade afete os conhecimentos; elas estão copresentes de tal maneira que são oferecidas à refutação, à discussão, quer dizer, ao diálogo: "Esta natureza, alguns outros a alcançaram, mas de maneira insuficiente" (Phys. I.9, 191b 22).

A copresença dos conhecimentos é uma modalidade necessária do horizonte de retrospecção; é por aí que S pode totalizá-las e se servir delas na sua pesquisa (isso é o que se chama, hoje, de "referências", e que figuram no fim de artigos sob a forma bibliográfica). Essa copresença não é apagada quando o sábio medieval fala da opinião dos "antigos". Que haja "antigos" não significa que a ciência ela mesma possa ser qualificada como "antiga". Apagar a copresença supõe uma ruptura na estrutura do horizonte de retrospeção, isto é, um estatuto diferente para certos conhecimentos que brotam de repente sobre todos: se certos conhecimentos se tornam antigos, é que, no fim, todos são tocados por historicidade. No entanto, a historicidade não é facilmente reconhecida no que concerne ao conhecimento científico por causa do caráter atemporal geralmente atribuído à verdade. Devemos perguntar-nos quando, como e por que advém a ruptura. Quando se abre o Dialogo sopra i due massimi sistemi del mondo (1632), de Galileu, chama-nos a atenção o fato de haver um "diálogo" entre Ptolomeu e Copérnico; aparentemente, estamos no sistema da copresença. Contudo, desde o primeiro dia do diálogo, o ataque contra o sistema de Ptolomeu se faz com o auxílio de descobertas astronômicas dos anos 1609-1613; a existência de novae, por exemplo, mostra que há muita mudança no mundo "supralunar" e que ele partilha esse fenômeno com o mundo "sublunar" em que consiste nossa terra. Foi entre os séculos XVII e XVIII que a estrutura do horizonte de retrospecção das ciências se modificou; foi durante o mesmo período que surgiram obras destinadas a descrever a história das disciplinas. Na segunda metade do século XVIII, o fato de as ciências terem uma história torna-se uma banalidade, como se vê no artigo "Mathématiques de 1'Encyclopédie": 
Art. Mathématiques de l'Encyclopédie: a respeito da história dessa ciência, no momento presente nós temos tudo o que podemos desejar sobre esse assunto, desde a obra que M. de Montucla publicou em dois volumes em $4^{\circ}$, sob o título de história das matemáticas, e que compreende até o fim do séc. XVII (ENCYCLOPÉDIE, t. X, 1765, p. 189a).

A obra de Montucla (1758) não é isolada: o inglês John Priestley aborda a eletricidade (1767), a visão, a luz e as cores (1772): Jean-Sylvain Bailly, a astronomia (História da astronomia antiga, 1775; História da astronomia moderna, 1785); E. Reichard tinha, dez anos antes, tratado da história da gramática alemã (Versuch einer Historie der Deutschen Sprachkunst, Hamburgo, 1747). O historiador não é o sujeito da ciência que é seu objeto; ele pode, a rigor, partilhar o horizonte de retrospecção de $\mathrm{S}$, seus trabalhos podem figurar nele, mas o que ele produz pertence às modalidades diferentes e específicas do trabalho científico.

$\mathrm{O}$ que pode se passar no funcionamento do sistema científico clássico para que se assista a uma tal ruptura? Dito de outra forma, sob que condições nós escapamos da copresença do horizonte de retrospecção? A temporalização corresponde ao desenvolvimento da categoria de "descoberta": o tempo dá lugar a alguma coisa de novo. É nessa época que se veem aparecer as querelas de prioridade (por exemplo, entre Newton e Leibniz sobre o cálculo diferencial), que são muito diferentes das querelas habituais sobre os plágios ${ }^{6}$. Esse tipo de querela supõe primeiro que o mesmo conhecimento seja acessivel a dois sujeitos diferentes. Não é questão que um possa apresentar um conhecimento e o outro, um outro, e que eles sejam incompativeis; o conhecimento é dotado de unicidade. Notemos que não se trata absolutamente de uma necessidade: na Antiguidade greco-latina, ainda que as "escolas" dessem visões incompativeis do mundo, elas ${ }^{7}$ coexistiam entre si, como faziam as escolas chinesas ou indianas. A querela de prioridade supõe, em seguida, e é uma evidência, que o acesso ao conhecimento se faça no tempo. Os clássicos tematizaram essa ideia de uma temporalidade dos conhecimentos graças à noção de progresso. Logo, existe história das ciências porque há o progresso das ciências. Na segunda metade do século XX, criticou-se muito essa noção por tudo que ela tinha de unilateral e universal. Não é por menos que, enquanto categoria sobre a qual os homens, em dado momento, pensaram inscrever suas atividades, ela é a chave da temporalização e, portanto, da historicização da ciência. Incidentemente, o fato de que haja progresso supõe que em tempos anteriores não se podia ter acesso aos mesmos conhecimentos; o passado da ciência não tem a mesma consistência que seu presente ${ }^{8}$.

Evidentemente, a estrutura do horizonte de retrospecção não mudou espontaneamente, assim como os historiadores não escolheram repentinamente estender seu domínio de conhecimento. Foi preciso que alguma coisa mudasse na própria estrutura do domínio de objetos, isto é, o próprio sistema científico. Os historiadores têm frequentemente insistido sobre esse ponto. A instrumentalização gera novas descobertas e novos objetos surgem nos horizontes do sábio, de

\footnotetext{
O plágio supõe que o plagiador não seja o autor do que afirma ter escrito, não simplesmente porque ele vem depois, mas explicitamente porque ele fez uma cópia; a querela de prioridade, quando ela acontece, admite a autenticidade das descobertas, ela questiona quem foi o primeiro a descobrir, mas se entende que os protagonistas têm igualmente direito ao título de descobridores.

7 "Elas", as escolas. [N. do T.]

8 Isso não significa que a ciência do passado seja uma ciência passada; nem que se considere que o futuro das descobertas seja infinito: no artigo "encyclopédie" da Encyclopédie, Diderot defende a ideia de que as matemáticas de sua época tinham atingido um ponto para além do qual elas não podiam mais avançar.
} 
sorte que esse horizonte não possa ser reproduzido tal qual: ele se altera. Além disso, nós nos encontramos diante de uma fase decisiva do crescimento exponencial de cientistas ${ }^{9}$; a organização muda (academias, coleção de instrumentos) e, desde então, a competição toma um novo aspecto. Já observamos que o começo da história das ciências deve ser pesquisado, na França, nos elogios fúnebres que o secretário perpétuo, Fontenelle, redigia por ocasião da morte de cada acadêmico. Desde que haja uma comunidade instituída, os mortos e as substituições de suas vagas produzem, com efeito, um ritmo, uma temporalidade. Mas os relatos de vida ${ }^{10}$ não constituem um esboço de história da ciência apenas se os heróis forem conhecidos como autores de descobertas que fazem parte do progresso da ciência.

Parece-me que não se pode tratar seriamente da questão da história das ciências sem estudar a constituição e a estrutura dos horizontes de retrospecção, assim como a maneira pela qual os domínios do objeto são afetados pela temporalidade, o que chamamos de "modos de historicização".

Nos anos 1970, nós nos batíamos com uma concepção excessivamente idealista da ciência. Primeiro, a definição do sistema de objetos parecia ir por si mesma (e nós a confundiamos com a do domínio dos objetos): havia "entidades" que correspondiam a "conhecimentos linguísticos"; estes eram, por definição, abstratos e universais: havia "ciência" uma e por toda parte semelhante a ela mesma. A única questão que podia surgir para o historiador era, a rigor, saber se essa ciência tinha existido sempre (a resposta em geral era "não"; e havia o esforço de datá-la: o comparatismo, Saussure, Chomsky). Da unicidade do objeto resultava uma subavaliação da dimensão espacial. O objetivo era descrever as descobertas que estavam ocorrendo na linha temporal da evolução "da" ciência. Que essas descobertas tenham acontecido aqui ou ali não havia nenhuma importância intrínseca (o espaço servia, quando muito, à identificação ou à análise do deslocamento dos centros de produção). Estimava-se não haver necessidade de sistemas de interpretantes, porque nós não deixávamos jamais o domínio "da" ciência, dotado por essência de uma capacidade de autorreflexividade infinita. Evidentemente, a história das ciências da linguagem era, desse modo, um domínio muito pobre: ou se tolerava um domínio "pré-científico" que era abordado como uma curiosidade, ou - e de um ponto de vista teórico, isso vinha assim mesmo - o que acontecia além (não para os "historiadores" das ciências, mas para os estudiosos da Antiguidade e os medievalistas, por exemplo).

A constituição de uma comunidade de historiadores das ciências da linguagem foi decisiva, porque ela relacionou especialistas dos quais uns abordavam a ciência moderna (da qual o modo de historicização se efetuou sob a categoria do "progresso" e da qual os outros vinham de um domínio marginalizado e exerciam seu talento, por exemplo, entre os filólogos). Tomemos o caso de Anders Ahlqvist. Ele tinha um objeto não abstrato: l'Auraicept na nEces ("O manual elementar dos poetas", ver Ahlqvist, 1983), um tratado, que existe empiricamente (manuscritos que se recopiam), em um certo contexto social. A modalidade

9 A palavra "cientistas", como usada aqui, corresponde à expressão francesa personnel scientifique, que se refere, nesse contexto, a todos os envolvidos na organização e desenvolvimento das ciências, e não somente aos pesquisadores. [N. do T.]

10 Que se tenha tido o trabalho de escrevê-los e conservá-los supõe que globalmente a sociedade tenha esses personagens como mais importantes; isso não significa que seus trabalhos, considerados em sua inteireza, sejam julgados como "a história do progresso de sua ciência". Em Roma, também os gramáticos eram homens dignos de interesse; o De Grammaticis illustribus de Suetônio não é, contudo, verdadeiramente uma história da gramática. 
intrinseca pela qual seu objeto era afetado pela temporalidade era o acréscimo de comentários (assim, não havia jamais substituição pura e simples, os conhecimentos - de fato, textos - podiam perdurar indefinidamente), não era um simples parâmetro externo que vinha da representação do historiador. Enfim, a acessibilidade dos conhecimentos encerrados em um texto não era direta para quem quer que tivesse uma simples cultura de linguística contemporânea. Era preciso um forte sistema de interpretantes (de fato, fortes conhecimentos especializados), sem o qual o texto era incompreensivel.

Uma vez reconhecido o modelo, era fácil de estender e acrescentar sem complexo, ao domínio das ciências da linguagem, objetos similares: os escólios estoicos sobre os textos de Dionísio, o Trácio ou os comentários da primeira gramática tamil, por exemplo, e também os comentários medievais de Aristóteles. Foi muito mais demorado reconhecer o impacto que podia ter esse reconhecimento sobre a representação teórica de nosso trabalho de historiador e suas consequências sobre nossa concepção de ciência. Foi preciso levarmos em conta as modalidades intrínsecas de afetação temporal dos objetos (sua "historicização", isto é, seu modo de ser na "história real"). Isso pode parecer uma questão abstrata e filosófica. De fato, é para o historiador uma questão empírica e crucial que gera novos objetos. Inversamente, o nascimento da história das ciências não é simplesmente o nascimento de uma nova disciplina; é, como já dissemos, o advento da historicidade no conceito que temos da ciência ${ }^{11}$. Esse advento possui consequências filosóficas consideráveis sobre o que temos muita dificuldade de pensar. Oscilamos, de fato, entre duas categorizações extremas: de um lado, o "progresso"; de outro, o "relativismo" e/ou o "historicismo". Apesar das críticas da noção de "progresso" (naturalmente, ele não é linear, podemos igualmente trazer à luz as descontinuidades e nem sempre ele é identificável etc.), seu papel categorial não é simétrico em relação àquele do relativismo. Essa noção representou um papel considerável na historicização do conceito de ciência. O relativismo quanto a ele mesmo gera paradoxos tais que muitos filósofos preferem rejeitá-lo para proteger o conceito tradicional de "ciência", como conjunto de proposições verdadeiras. De fato, é absolutamente necessário que os filósofos trabalhem seriamente sobre as consequências conceptuais da historicização da ciência.

É preciso, naturalmente, refletir sobre a aparição da história das ciências. No que concerne às ciências da linguagem, começamos a dispor de informações confiáveis. A contar do Renascimento, reconhecemos notáveis mudanças no funcionamento do domínio dos objetos. Há, primeiro, a aparição de novos dados, o que chamamos de "revolução tecnológica da gramatização": sob a pressão do nascimento dos Estados-nação, dotam-se os vernáculos de instrumentos linguísticos (gramáticas, dicionários), enquanto as grandes descobertas levaram, simultaneamente, a começar a gramatização sem precedente na história da humanidade do conjunto das linguas do mundo (AUROUX, 1992). Paralelamente, a população dos sábios, eruditos ou amadores esclarecidos que se consagram pouco ou muito aos fenômenos linguísticos conhecem um crescimento demográfico jamais igualado. Essa densidade chamava a uma organização: ao longo dos séculos XVII e XVIII nós vimos nascer academias e sociedades eruditas que

11 Evidentemente, uma vez que dispomos do conceito de "historicidade da ciência", as práticas científicas, quaisquer que sejam suas datações e seus modos de historicização, pertencem à história. Cabe ao historiador fazer a história da "ciência antiga", mesmo que seu modo de historicização não seja subsumível para os sujeitos que a praticavam sob a categoria (desconhecidá para eles) de historicidade. 
consagram uma parte notável de sua atividade à linguagem; nas últimas décadas do século XVIII e nas primeiras do século XIX aparecem os primeiros periódicos "linguísticos". Essa mudança de dimensão do domínio de objetos leva necessariamente à concorrência e à necessidade de um conhecimento dos trabalhos de outros sábios e eruditos. Empiricamente, podemos constatar que o nascimento da história da ciência da linguagem se desenvolve na reestruturação dos horizontes de retrospecção que essa mudança de dimensão acarreta.

À margem, encontram-se, primeiro, listas de obras nos projetos das bibliotecas: na França, desde a Biblioteca escolhida de Le Clercq (1703-1713) até a Biblioteca gramatical abreviada de Changeux (1773); Bullet faz preceder suas Memórias sobre a língua céltica (1754) da lista comentada das obras que ele consultou; Court de Gébelin procurava consagrar o tomo 10 do Mundo primitivo a uma notícia dos livros que o autor leu sobre esses objetos, que "será como a história crítica e racional das pesquisas anteriores sobre as matérias" (Prospectos do Mundo primitivo, aparecido nas Efemérides do Citoyen). Em 1773, D. Thiébault redige sua Carta à Monsieur Pinglin sobre a história da ciência gramatical; em 1796, F. Thurot publica seu famoso Quadro dos progressos da ciência gramatical, como prefácio à tradução francesa do Hermès de John Harris; em 1816, J. D. Lanjuinais, quando procede a uma reedição anotada (em um sentido muitas vezes crítico) da História natural da palavra de Court de Gébelin, acrescenta aí um prefácio que é uma história das teorias linguísticas. Nota-se já uma dissociação entre a representação dos trabalhos "gramaticais" e aqueles que se interessam pelo comparatismo. Assim, Volnei, cujo Discurso sobre o estudo filosófico das línguas (pronunciado na Academia Francesa em 1819) é uma história racional das pesquisas históricas e comparativas sobre as línguas, não propõe praticamente nenhum item comum com os outros (a sobreposição é também relativamente fraca para Lanjuinais). Existe o mesmo tipo de série para os países de língua alemã (AUROUX, 1987, p. 22). Todas as grandes compilações sobre as línguas do mundo da virada do século (por exemplo, Mithridates de Christoph Adelung, 1806-1817 ou o Atlas etnográfico do globo de A. Balbi, 1826) comportam uma parte "histórica".

Constata-se uma exteriorização com relação ao horizonte de retrospecção. Mesmo para os autores que, como Thiébault ou Adelung, devem ser considerados como produtores ativos no domínio (não é o caso de Lanjuinais ou de Thurot), a atividade histórica não entra no texto do seu trabalho de linguista; Court de Gébelin não dará continuidade ao seu projeto. Nessa exteriorização, os elementos "históricos" adquirem a independência e o estatuto de objeto. Mesmo se lhes acontece confundir fisicamente, o sujeito do saber $(\mathrm{S})$ e o historiador $(\mathrm{H})$ não são idênticos. O que se passa fora do horizonte de retrospecção pode ser reinjetado nele, mas não haverá o mesmo estatuto que as referências que estão em copresença com a atividade de S. É essa atividade originária que permite o "rompimento" no horizonte de retrospecção: doravante, ao lado das referências, há um lugar para elementos (de fato, uma representação bastante geral) que são afetados por uma marca temporal "passada". Seu estatuto cognitivo não é idêntico ao das referências: S não tem que sustentar seu valor de verdade. O "sistema de objetos" do historiador e o conjunto de referências do linguista não são evidentemente independentes. Já se viu como os horizontes de retrospecção diferentes daqueles que se interessam ao comparatismo e à história das línguas e daqueles que se preocupam pela pura gramática induziam sistemas de objetos históricos 
diferentes. Notar-se-ão, mais geralmente, comunidades de objetos entre os dois. Se levarmos em conta o horizonte de retrospeção dos autores anteriores à aparição da história, como Linacre ou Escalígero (ver COLOMBAT, 2006 neste número de HEL), denuncia-se imediatamente uma anomalia: os autores medievais estão ausentes. Eles estarão ausentes por praticamente meio século do sistema de objetos dos historiadores. O horizonte de retrospecção possui uma restrição que não afeta o território do historiador: ele acabou e o "esquecimento" aí possui uma função criativa. Referências são periodicamente "retiradas" do domínio de copresença do horizonte de retrospecção em função de interesses cognitivos do momento ou sob a influência de outros fatores mais aleatórios (perdas de fontes, por exemplo). A ausência de referência não significa necessariamente uma ausência total no horizonte de retrospecção; certos elementos podem figurar no anonimato do conhecimento comum. Assim, desvendamos incontestáveis elementos medievais em Port-Royal (significação dos objetos de nossos pensamentos versus significação da forma e da maneira de nossos pensamentos) ou Beauzée (teoria da extensão das ideias). Certos "esquecimentos" procedem de um afastamento voluntário, por exemplo, o dos ideólogos pelos comparatistas alemães (SCHLIEBEN-LANGE, 1984). Outros são mais complexos. Pode-se pensar que a ausência de referenciação ulterior dos autores que figuram na Enciclopédia de d'Alembert e Diderot provém largamente da sintese realizada pela obra e cujos resultados passaram ao estatuto de conhecimento comum. Bem-entendido, o historiador não pode proceder dessa maneira; por princípio, ele deve se preocupar com todo o domínio de objetos, passado ou presente. Isso não significa que a tarefa seja restituir a história real na sua "realidade"; isso não é mais atingivel do que a opacidade do mundo natural. O historiador, como todos os seus colegas científicos, constrói representações teóricas susceptiveis de serem corroboradas/invalidadas pelos dados empíricos ${ }^{12}$. Algumas são melhores do que outras; todas são necessariamente parciais.

O trabalho histórico, a estrutura dos horizontes de retrospecção e os modos de historicização podem ter relações mais ou menos fortes. Na historicização por acréscimo, tudo se reduz ao texto e seus comentários. Existe outro modo de historicização em que prima a existência da permanência de um objeto pertencente ao mundo real - é os das técnicas. O objeto técnico está lá diante de nós; nós o preservamos, o reconstruímos, o desmontamos, pegamos pequenos pedaços dele para integrá-los a novos objetos. Não se pode mais qualificar o modo de historicização do objeto técnico a não ser sustentando que a roda é um dos antepassados da locomotiva a vapor (transformação do movimento linear do pistão no movimento circular das rodas) ${ }^{13}$. Da mesma forma, um dicionário francês pode ter por ancestral um dicionário latino, que, tornado um dicionário latino-francês, voltou, depois vive da sua própria vida de novo objeto técnico. Mas, de maneira geral, na ciência moderna, o modo de historicização depende largamente da constituição e da estrutura do horizonte de retrospecção. A ciência, de fato, não é uma realidade do mundo externo relativamente intangivel sobre o des-

\footnotetext{
12 "A cidade historiada está diante da 'história' como um grupo de jogadores diante de grande quantidade de peões. Cada um escolhe os seus e lhes anuncia o valor. Às vezes um dos jogadores exige que um outro lhe mostre seus peões ou, mais ainda, ele tira outros peões para bloquear o adversário. Às vezes, também, a cidade inteira mantém um dos jogadores sob seus anúncios. Mas é essa estratégia que nenhum jogador deveria escolher, porque existem peões que bastam para bloquear o adversário" (cf. AUROUX, 1979, p. 11). [Nessa passagem, o autor usa metáfora de jogos de cartas, como do "jass", jogo que se desenrola por meio de annonces/anúncios feitos pelos jogadores (N. do T.)].

13 Cf. Simondon (1958).
} 
gaste do tempo como são os monumentos; ela depende das atitudes individuais e de suas atitudes, é preciso produzi-las; dito de outra forma, é preciso reproduzir a ciência.

O exemplo mais claro do papel da estruturação do modo de historicização (e corolariamente do horizonte de retrospecção) nos é fornecido pelo desenvolvimento da linguística nos países de língua alemã no século XIX. O elemento essencial se joga na construção da universidade, no crescimento da população que ensina e de estudantes e no estabelecimento de novas regras. Veem-se as premissas da instauração do seminário por F. A. Wolf (especialista de Homero) ao fim do século XVIII (HÜLTENSCHMIDT, 1985). Em um seminário, os estudantes não são passivos; eles têm leituras das quais devem dar conta diante de seus colegas; paralelamente, devem apresentar seus trabalhos perante seus colegas e professores. O desenvolvimento da Universidade prussiana (largamente devido à impulsão inicial de F. W. Humboldt) aumentou o fenômeno: pressão demográfica, publicações, doutorado. Nesse sistema, um doutorado obedece a duas exigências: ele deve dar conta de trabalhos anteriores e apresentar qualquer coisa de novo. O progresso é uma exigência da ciência. Os neogramáticos, 50 anos mais tarde, vão utilizar plenamente o sistema. Os novos conhecimentos serão repertoriados como descobertas; conhecer-se-ão suas datas e serão identificados pelo nome de seus inventores (lei de Grimm, lei de Grassman etc.). Imagina-se também como evolui a estrutura do horizonte de retrospecção. No que concerne à história, a Geschichte der Sprachwissenschaft und orientalischen Philologie in Deutschland, seit der Anfange des 19. Jahrhunderts mit einem Rückblick auf frühere Zeiten (1869), de Th. Benfey, fornece a imagem heroica do nascimento dessa ciência. Benfey é um dos protagonistas do novo modo de historicização e construiu os elementos de autorrepresentação de sucesso de seus pares. Doravante, figura no horizonte de retrospecção dos linguistas formados nesse contexto uma fábula referente ao estatuto de "ciência" à disciplina linguística. A obra de Benfey não é sem interesse, mas sua recuperação nos horizontes de retrospecção corresponde a um empobrecimento considerável (ver as páginas "históricas" que introduzem o Curso de linguistica geral, de F. de Saussure).

O discurso científico segue uma ordem de argumentação que exclui a temporalidade. Quando se introduzem os elementos históricos (isto é, datados), seu valor de verdade ${ }^{14}$ é por essência sem efeito sobre a argumentação (é o que temos chamado de "paradoxo historiográfico" em Auroux [1995]). Sua presença no horizonte de retrospecção não é sem efeito sobre o funcionamento científico e o modo de historicização. Os neogramáticos souberam estruturar um horizonte de retrospecção que permite um funcionamento científico satisfatório (em certos limites que não nos interessam aqui). É preciso notar, em particular, sua maneira de identificar as descobertas e de inscrevê-las no horizonte de retrospecção. Por aí, eles dão consistência ao modelo de "ciência".

Pode-se perguntar o que se passa no mundo moderno quando se abandona esse tipo de estruturação. Ora, é efetivamente o que vem em seguida a uma mudança de tipicalidade no modelo da ciência. Doravante, o tipo que serve de referência à noção de "ciência" é a física matemática. Assim, as atividades afastadas desse tipo (a gramática, a gramática comparada) tornam-se problemáticas. Vi-

14 Queremos dizer que o valor seria concedido por um trabalho respectivo das metodologias do historiador. 
ram-se autores que reclamam da linguística (YNGVE, 1986, por exemplo) proclamarem que ela não é ainda uma ciência e que se tornará tal se no futuro se seguirem suas proposições, que fazem radicalmente tabula rasa do passado. $\mathrm{O}$ mínimo que se pode dizer é que o modo de historicização tornou-se caótico. Um fosso se criou entre o historiador e o sujeito da ciência. Esse último tornou-se incapaz de responder a uma simples questão de datação de descoberta (por exemplo, quando se reparou o fenômeno de ergatividade ou se definiu o imperfeito?): isso não pode lhe interessar porque contradiria sua tese sobre a ciência e seu futuro. O horizonte de retrospecção não é vazio, mas parcelado, sem profundidade temporal e fragmentado em função dos interesses de cada um.

A situação é preocupante. Uma ciência que não tem história é uma ciência morta, uma ciência que não existe mais. Os mortos não têm futuro.

\section{MODES OF HISTORICIZATION}

Abstract: To be an historian of sciences is to be able to build chronologies and causal links (the latter in fact is what distinguishes the historian from the historiographer, who only tells stories, even though a narrative is an intrinsic explanatory structure), moreover, to be an historian of sciences is to be able to build representations and explanations.

Keywords: History of science. History of Linguistics. Meta-history and chronology. Causal links. Horizon of retrospection.

\section{REFERÊNCIAS}

AHLQVIST, A. The early Irish linguist: an edition of the canonical part of the Auraicept na nÉces. Commentationes Litterarum Humanorum, LXXIII, Heksingfors, Societas Scientarum Fennica, 1983.

AUROUX, S. La sémiotique des encyclopédistes. Paris: Payot, 1979.

AUROUX, S. Histoire des sciences et entropie des systèmes scientifiques. Les horizons de retrospection. In: SCHMITTER, P. (éd.). Geschichte der Sprachttheorie 1: Zur Theorie und Methode der Geschichtsschreibung der Linguistik. Tübingen: Gunter Narr, 1987. p. 20-42. (1ère parution en 1986 dans Archives et Documents de la SHESL, 7, 1-26).

AUROUX, S. La révolution technologique de la grammatisation. Liège/Bruxelles: Mardaga, 1992.

AUROUX, S. L'histoire des sciences et le paradoxe historiographique. Le Gré des Langues, v. 8, p. 45-63, 1995.

AUROUX, S. La raison, le langage et les normes. Paris: PUF, 1998.

AUROUX, S.; COLOMBAT, B. L'horizon de rétrospection des grammairiens de l'Encyclopédie. Recherches sur Diderot et l'Encyclopédie, n. 2, p. 111-152, oct. 1999. Disponivel em: https://journals.openedition.org/rde/821. Acesso em: 19 fev. 2021.

COLOMBAT, B. Les références aux anciens et aux modernes chez les grammai- 
riens latins du 16e siècle (Linacre, Scaliger, Ramus, Sanctius). Histoire Épistémologie Langage, v. 28, n. 1, p. 25-50, 2006. Disponivel em: https://www. persee.fr/docAsPDF/hel_0750-8069_2006_num_28_1_2865.pdf. Acesso em: 19 fev. 2021.

GROTSCH, K. Sprachwissenschaftsgeschichtsschreibung. Ein Beitrag zur Kritik und zur historischen und methodologischen Selbstvergewisserung der Disziplin. Göppingen: Kümmerle Verlag, 1982.

HÜLTENSCHMIDT, E. Wissenschafthistoriographie und soziologische Theorie. F. A. Wolf und die Entstehung der modernen Philologie und Sprachwissenschaft. Gumbrecht. In: ULRICH, H.; LINK-HEER, U. (ed.). Epochenschwellen und Epochenstrukturen im Diskurs der Literatur - und Sprachhistorie. Frankfurt: Suhrkamp, 1985. p. 341-356.

SCHLIEBEN-LANGE, B. Vom Vergessen in der Sprachwissenschaftsgeschichte. $\mathrm{Zu}$ den Ideologen und ihrer Rezeption im 19. Jahrhundert. Zeitschrift für Literaturwissenschaft und Linguistik, n. 53/54, p. 18-36, 1984.

SCHMITTER, P. Untersuchungen zur Historiographie der Linguistik. Tübingen: Gunter Narr Verlag, 1982.

SCHMITTER, P. Historiographie und Narration. Metahistoriographische Aspekte der Wissenschaftgeschichtsschreibung der Linguistik. Séoul: Sowaldalmedia; Tübingen: Gunter Narr Verlag, 2003.

SIMONDON, G. Du mode d'existence des objets techniques. Paris: Aubier-Editions Montaigne, 1958.

YNGVE, V. H. Linguistics as a science. Bloomington: Indiana University Press, 1986. 